\title{
Corrosion and Strength Behaviors in Prestressed Tendon under Various Tensile Stress and Impressed Current Conditions
}

\author{
Bang-Yeon Lee, ${ }^{1}$ K. T. Koh, ${ }^{2}$ M. A. Ismail, ${ }^{3}$ H. S. Ryu, ${ }^{4}$ and S. J. Kwon ${ }^{5}$ \\ ${ }^{1}$ School of Architecture, Chonnam National University, 77 Yongbong-ro, Buk-gu, Gwangju 61186, Republic of Korea \\ ${ }^{2}$ Structural Engineering Research Institute, Korea Institute of Civil Engineering and Building Technology, 283 Daehwa-dong, \\ Goyangdae-ro, Ilsanseo-gu, Goyang-si, Gyeonggi-do 10233, Republic of Korea \\ ${ }^{3}$ Department of Civil and Construction Engineering, Faculty of Engineering and Science, Curtin University Sarawak, CDT 250, \\ 98009 Miri, Sarawak, Malaysia \\ ${ }^{4}$ Hanyang Experiment and Consulting Co., 1271 Sa 3-dong, Sangrok-gu, Ansan 15588, Republic of Korea \\ ${ }^{5}$ Department of Civil and Environmental Engineering, Hannam University, Daejeon 34430, Republic of Korea
}

Correspondence should be addressed to S. J. Kwon; jjuni98@hannam.ac.kr

Received 24 February 2017; Accepted 9 April 2017; Published 23 May 2017

Academic Editor: Xiao-Jian Gao

Copyright (C) 2017 Bang-Yeon Lee et al. This is an open access article distributed under the Creative Commons Attribution License, which permits unrestricted use, distribution, and reproduction in any medium, provided the original work is properly cited.

\begin{abstract}
Corrosion occurs more rapidly under high tensile stress and this leads to several problems like degradation of serviceability and structural performance in PSC (prestressed concrete) structures. In this paper, impressed current method, so-called ICM, was applied to tendons under tensile loadings of $0.0,20.0,40.0$, and $60.0 \%$ of ultimate load. With induction of 20 volts for 24 hours to tendon under tensile stress, loading was induced to failure and the ultimate load was evaluated with varying corrosion behaviors. The changing mechanical behaviors in the same corrosive conditions were evaluated under different initial prestressing levels. With increasing initial prestressing load, corrosion occurred more rapidly and corrosion amount also increased linearly. The ultimate load accordingly decreased with increasing initial prestressing and corrosion amount. The relationships between prestressing levels and corrosion behaviors were quantitatively obtained through regression analysis. The measured current during applied voltage and the related corrosion amounts were also dealt with in this work.
\end{abstract}

\section{Introduction}

Concrete is a construction material with high compressive strength but low tensile strength, so that reinforcements are required in the region subjected to tensile stress. Normal structural steel is usually used as reinforcement due to clear design parameters such as yielding stress, yielding strain, and elastic modulus $[1,2]$. For long structural members, prestressing tendons are efficiently used as PSC (prestressed concrete) members since it can use total area as effective area, namely, compressive region through downing neural axis.

Tendon has almost the same Young's modulus as structural steel but higher ultimate strength, over 1,200 MPa, and wider elastic region [3, 4]. PSC has several engineering strong points such as reduction of self-weight, crack-free section, and easy construction of long member. The tendons inside sheath are always subjected to high tensile stress around $60 \%$ of ultimate strength. They are basically protected by grout but corrosion can be caused by imperfection of grouting and partial exposure to air. Corrosion initiation and propagation in reinforcement are accelerated when tendon is under tensile stress since the composition in reinforcement is loosened, which yields more rapid current density in given corrosive conditions $[5,6]$. So many structural degradations have been reported and they also required repair or restrengthening in a large scale [7-9]. Concrete specifications and structural codes have suggested more strict guidelines for corrosion control for PSC $[2,10,11]$. The corroded tendon causes not only reduction of serviceability such as more deflection and cracks but also reduction of bearing capacity in PSC girder [12-14]. Recently many NDTs (nondestructive techniques) have been adopted for detection of corrosion initiation and progress in existing PSC structures but they have limited applications due 


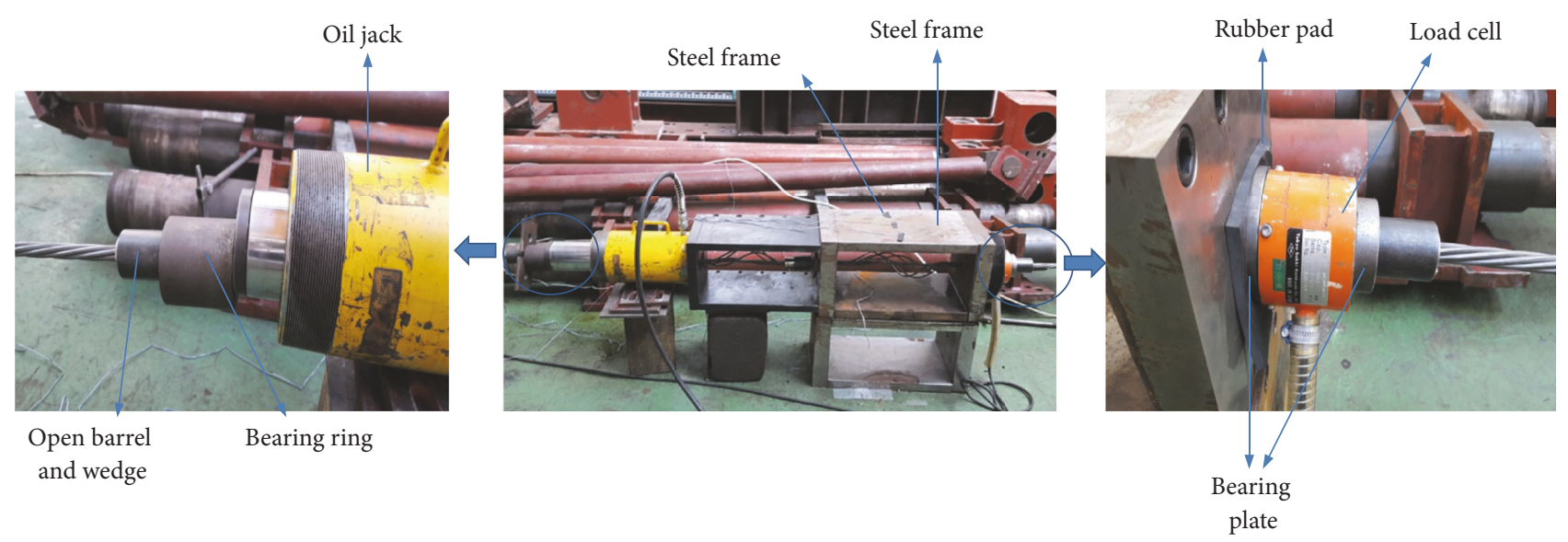

FIGURE 1: Test setup for loading and prestressing system.

to impedance of local signals, effect of cover concrete (sheath and grouting), and twisted section of strand [15-18].

There are many researches on accelerated corrosion for normal steel; however accelerated corrosion behavior in tendon subjected to high tensile stress is limitedly studied. In this work, normal tendons with $15.3 \mathrm{~mm}$ diameter were prepared and accelerated corrosion test was performed under different tensile loading levels from $0 \%$ to $60 \%$ of the ultimate load. For the acceleration corrosion test, ICM (impressed current method) was adopted, and transported currents, corrosion amounts, and the ultimate loads after ICM test were also evaluated. The relationships between corrosion behavior and mechanical characteristics were quantitatively obtained.

\section{Test Programs for Corrosion Acceleration and Loading Control}

2.1. Setup for Loading System. Steel frame with high strength was designed and prestressing to the desired level was carried out before acceleration of corrosion. Three different loading levels were adopted as $20 \%, 40 \%$, and $60 \%$ of the ultimate load. In order to avoid the current induced to data logger and sensors, rubber plates were fixed around load cell and bearing plate. Prestressing loss is caused by slip of wedge in open barrel during loading prestressing, so that corrosion acceleration is performed after completion of the desired prestressing through repeating jacking and inserting wedge. Figure 1 shows the test setup.

\subsection{Setup for ICM System}

2.2.1. Acceleration of Corrosion through IMC (Impressed Current Method). Accelerated corrosion was set up in the empty room of the frame. In the harsh environmental condition, few decades are needed for strength reduction in steel or tendon due to corrosion $[19,20]$. In the work, ICM was adopted for acceleration of corrosion, by which considerable reduction of strength can be expected within a short period. It is recognized as an efficient method for corrosion acceleration for monitoring cracking in cover concrete and reduction of strength in corroded steel [18, 21, 22]. Corrosion amount through exchange of $\mathrm{Fe}^{2+}$ ion can be calculated according to Faraday's Law as follows:

$$
M_{\mathrm{cor}}=\frac{c}{z F} \cdot \int q d t
$$

where $M_{\text {cor }}$ is corrosion amount (mol), $z$ is ion valence of Fe (equal to 2), $F$ is Faraday's number $(96,500), q$ and $t$ are current (Amp) and duration time (sec), respectively, and $c$ is assumed as experimental constant.

2.2.2. Measurement of Current and Corrosion Rust. The accelerated corrosion was performed in a corrosion cell inside the steel frame. The cotton towel with $75 \mathrm{~mm}$ width and $5 \mathrm{~mm}$ thickness was submerged in $3.5 \%$ of $\mathrm{NaCl}$ solution and the middle part of tendon was covered with the saturated towel, which induced chloride saturation on the tendon through capillary suction. In order to measure equivalent current induction, each strand was welded with wire and $20 \mathrm{~V}$ of electrical charge was applied. After accelerated corrosion for 24 hours, the given length of $75 \mathrm{~mm}$ was cut and submerged in $5.0 \%$ of $\mathrm{C}_{6} \mathrm{H}_{8} \mathrm{O}_{7}$ acid for removal of rust. The weight loss was evaluated through measuring the initial weight and the weight after ICM test. Figure 2 shows corrosion cell and removal of rust process.

The total procedure of tests for loading and accelerating corrosion is summarized in Table 1.

\section{Reduction of the Ultimate Load after Accelerated Corrosion Test}

\subsection{Variation of Current with Different Loading Levels}

3.1.1. Corrosion Current and Prestressing. With increasing prestressing level, the measured current also increases, and that is in line with the previous researches. When corrosive condition is stable, the concentration of $\mathrm{NaCl}$ in member under tensile stress is getting higher and thus ion current increases accordingly $[5,6]$. The measured current values are shown in Figure 3 with different prestressing levels. 


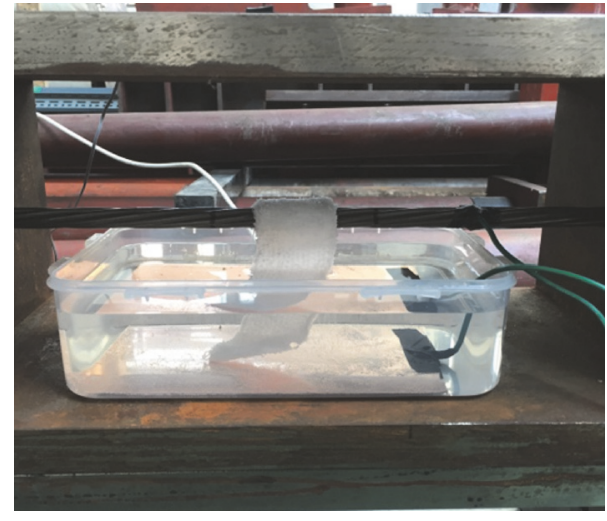

(a) Corrosion cell

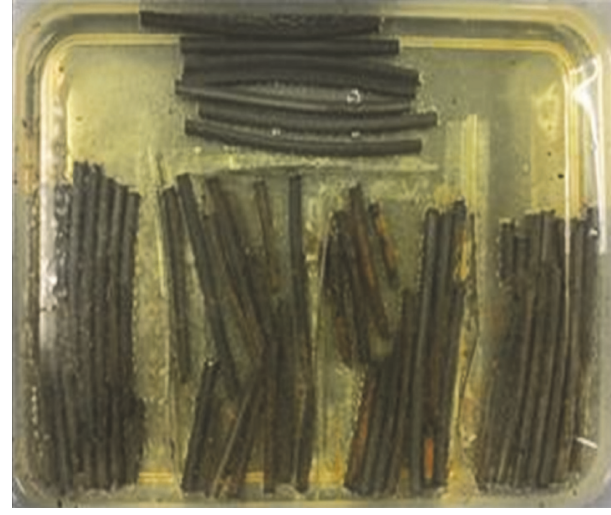

(b) Removal of rust in corroded tendon

FIGURE 2: Corrosion cell and rust removal process.

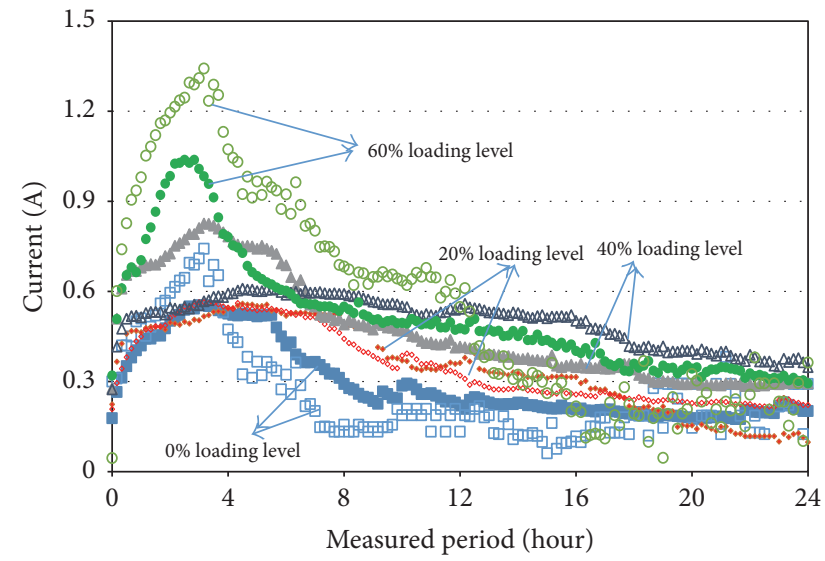

FIGURE 3: Changes in measured current with different prestressing level.

The increasing ratio of current with prestressing is $126.6 \%$ for $20 \%$ level, $175.4 \%$ for $40 \%$ level, and $193.9 \%$ for $60 \%$ level, respectively. Figure 4 shows the summation of current measurements in the same accelerated period.

3.1.2. Corrosion Weight with Different Stress Level. The corroded strands are twisted and deformed, so that it is difficult to cut with accurate length of $75.0 \mathrm{~mm}$. The test results for corrosion amount are plotted in Figure 5 with calculation results referring to Faraday's Law with 1.6 of experimental constant in (1). In the constant ICM condition, corrosion amount is evaluated to be proportional to summation of currents.

The differences from measurement and calculation can be inferred by several reasons like (1) measuring errors for corrosion amount and original length of tendon $(75.0 \mathrm{~mm})$, (2) usage of tab water, (3) variations of local conditions of temperature and towel saturation, and (4) imperfect attachment and welding for equivalent current inducement.

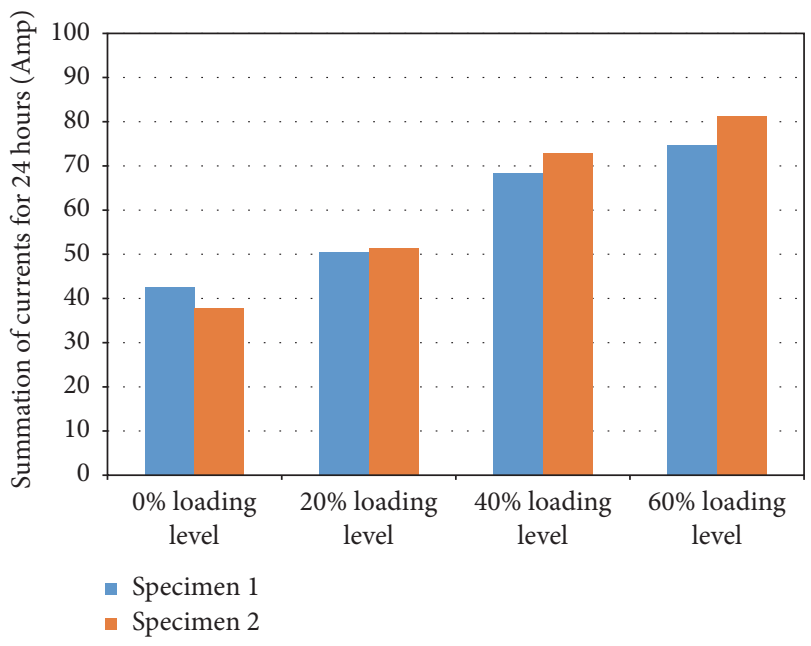

FIGURE 4: Summation of measurements with different prestressing level.

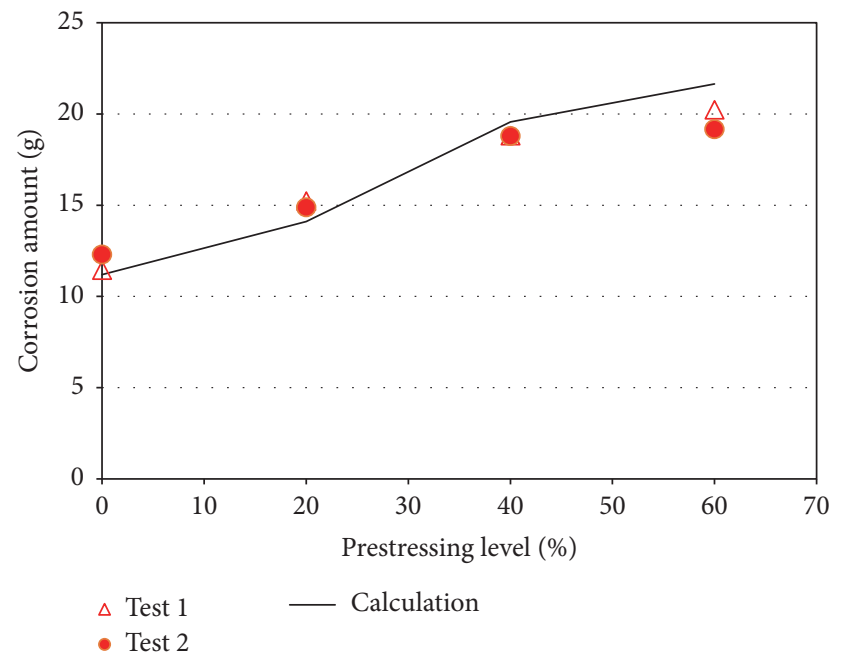

FIGURE 5: Corrosion amount with stress level. 
TABLE 1: The entire procedure for loading and corrosion tests.

\begin{tabular}{lcl}
\hline Step & Action & Related photos \\
1st & Installation of steel frame and tendon setup & \\
\hline
\end{tabular}

2nd Preparation of $3.5 \% \mathrm{NaCl}$ solution and saturation

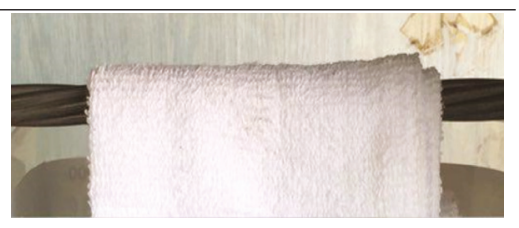

$3 r d$

Installation of bearing plate, barrel, and wedge

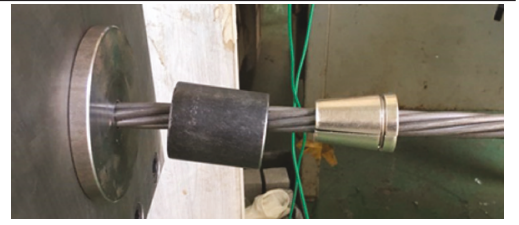

4th

Welding of strand and wire/attachment of gauge

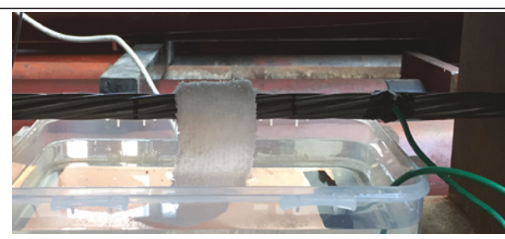

5 th

Prestressing to designed level (0\%,20\%, 40\%, and $60 \%$ of the ultimate loading)

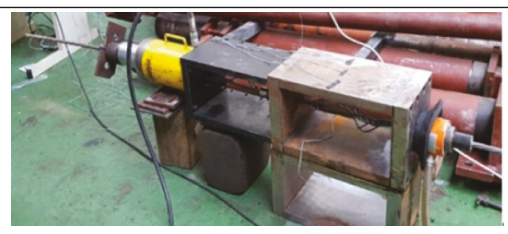

6 th

Performing ICM with $20 \mathrm{~V}$ for 1 day

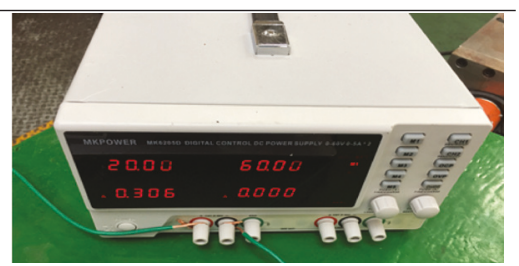

7 th

Loading to failure

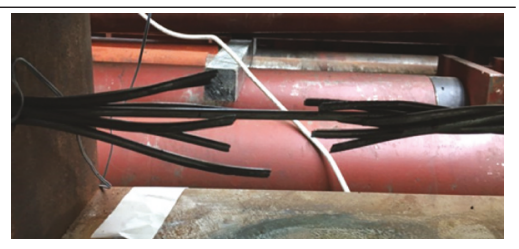

8 th

Measurement of corroded weight

\subsection{Reduction of the Ultimate Loading}

3.2.1. Reduced Prestressing Level during ICM Test. During accelerated corrosion test, tendons under high tensile stress are rapidly corroded, which allows a reduction in the area and additional release in the tendon. Unfortunately, only the initial and final loads were measured without decreasing prestressing stress during test since data logger might be overcharged in the applied current. In Figure 6(a), initial and final loadings are plotted after ICM test. Effective ratio can be determined as the ratio of residual prestressing force to initial prestressing force. 


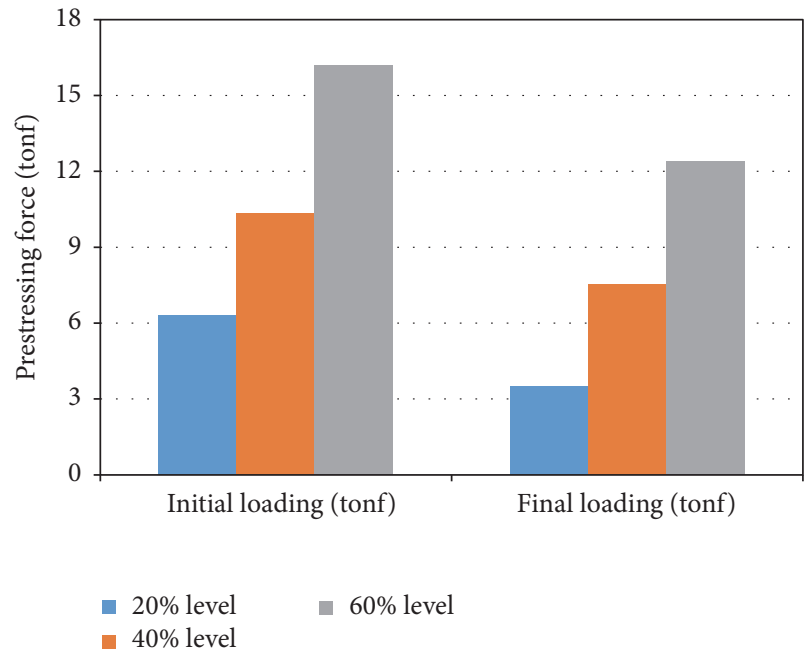

(a) Initial and final loads after corrosion test

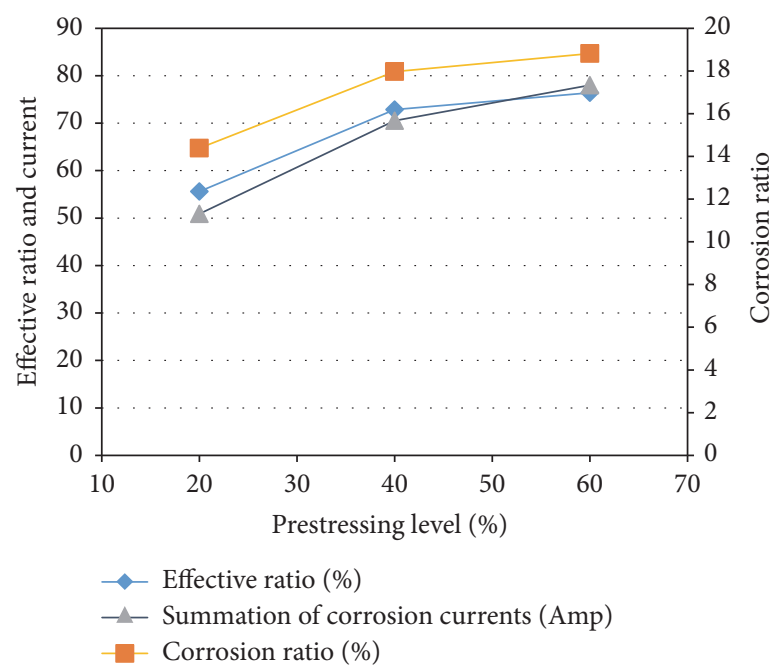

(b) Corrosion amount and effective ratio

FIGURE 6: Relationship between (a) initial and final loads after corrosion test and prestressing level and (b) prestressing level, corrosion ratio, and measured current.

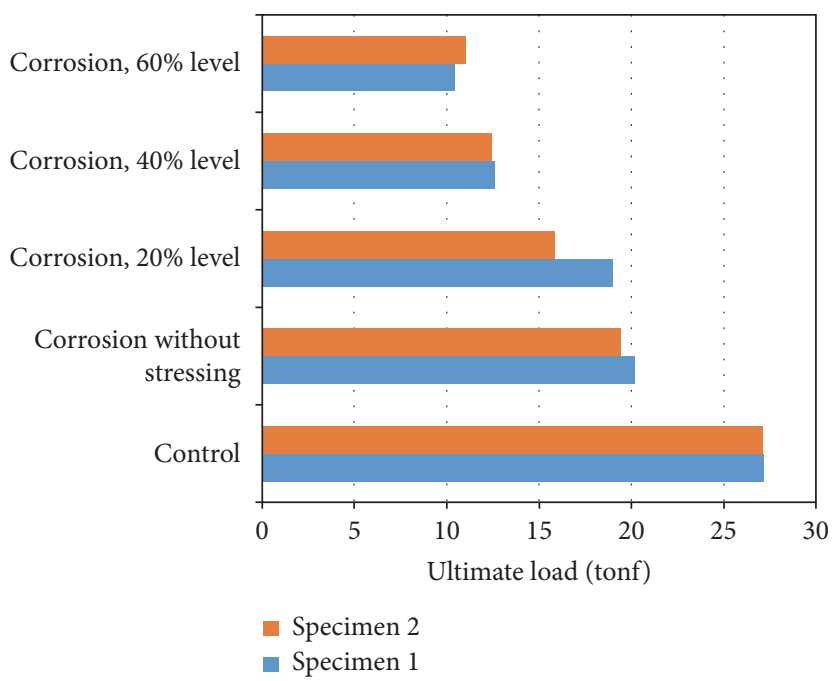

FIGURE 7: The relationship between ultimate loads and corrosion at different stress level.

The effective ratios with varying prestressing level are plotted in Figure 6(b) with measured corrosion currents and corrosion ratios. The effective ratios are $55.6 \%$ for $20 \%$ level, $72.8 \%$ for $40 \%$ level, and $76.4 \%$ for $60 \%$ level of prestressing, respectively. Effective ratio has similar pattern to the transported current and corrosion amount.

\subsubsection{Reduction in the Ultimate Loads due to Corrosion and Prestressing Level}

(1) Reduction of Ultimate Load with Different Prestressing Levels. After ICM test, tensile loading test to failure is performed for the evaluation of ultimate load. Ultimate load rapidly decreases with increasing prestressing level in the same corrosive condition. Figure 7 shows the relationship between ultimate loads and corrosion at different stress levels.

In the control case (without corrosion test), the average ultimate load is 27.16 tonf; however it decreases to $71.6 \sim 74.8 \%$ level after ICM test for 24 hours. In the same corrosive condition, the ultimate load decreases to $56.3 \sim 70.0 \%$ subjected to $20 \%$ of loading level, $45.8 \sim 46.4 \%$ for $40 \%$ level, and $38.4 \sim$ $40.6 \%$ for $60 \%$ level of prestressing. As shown in Figure 7, strength reduction due to the effect of accelerated corrosion accompanied by prestressing level is clearly evaluated.

(2) Changes in Stress-Strain Curve in the Corroded Tendon. In order to evaluate the mechanical behavior in the tendon under corrosion and tensile stress, stress-strain behavior is 


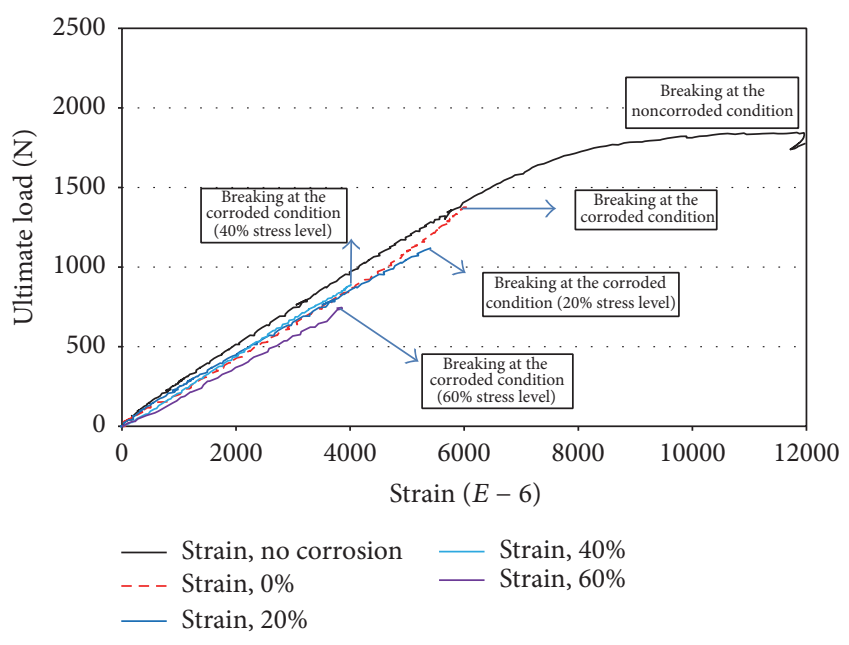

FIGURE 8: Stress-strain curve in corroded tendon after ICM test.

monitored after ICM test. The signal from load cell and gauge on the tendon surface out of corroded area (shown in Figure 2) are read in data logger. Although the strain gauge is attached on the twisted tendon out of corrosion area, stressstrain behavior can be approximately evaluated. The results are shown in Figure 8.

As shown in Figure 8, slight reduction of stiffness is evaluated in corroded tendon with increasing stress level which accelerates corrosion. With increasing prestressing level, clear reduction of ultimate strength and elongation to break are observed; however the stiffness degradation is not evaluated clearly due to twisted shape and local corrosion of tendon.

\subsection{Relationship between Prestressing Level and Corrosion} Behavior. In this section, the relationship between corrosion behavior and ultimate load was investigated considering the different prestressing levels. The results of corrosion ratio and ultimate load are plotted in Figure 9 with regression analysis results, which show clear linear relationships between corrosion ratio of weight and the ultimate load with high coefficient of determination (0.9658).

In the constant corrosive condition, the effect of prestressing on corrosion acceleration is plotted in Figure 10. Figures 10(a) and 10(b) are for the relationships between prestressing level and corrosion ratio and prestressing level and ratio of corrosion to control case (without prestressing), respectively. Clear increase in the ratio of corrosion is evaluated with high prestressing level with 0.9696 of $R^{2}$. With increasing prestressing level, corrosion velocity also increases to $124.3 \sim$ $126.5 \%$ for $20 \%$ level, $165.5 \sim 166.8 \%$ for $40 \%$ level, and 178.5 $189.8 \%$ for $60 \%$ level of prestressing with clear linearity relation.

\section{Conclusions}

In this work, corrosion behavior and the reduction of ultimate loading to failure were investigated considering prestressing levels. With increasing prestressing level, the corrosion

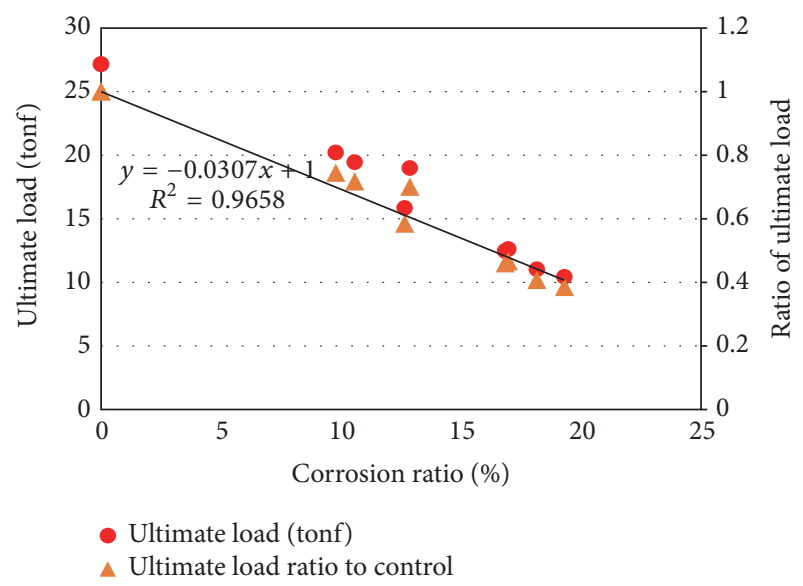

FIGURE 9: Relationship between ultimate load and corrosion ratio.

amount and ultimate load are evaluated to be changed linearly with higher current density. The conclusions can be drawn as follows:

(1) After 24 hours of accelerated corrosion test, effective ratios of prestressing force decrease to $55.6 \%$ for $20 \%$ level, $72.8 \%$ for $40 \%$ level, and $76.4 \%$ for $60 \%$ level of prestressing, respectively. Initial prestressing load is rapidly reduced by local elongation of tendon due to accelerated corrosion. The pattern of effective ratio with increasing prestressing level is much similar to those of corrosion ratio and summation of transported currents.

(2) With the increase in prestressing level in the same corrosive impressed current condition, corrosion ratio increases linearly, being 124.3 126.5\% for 20\% level, $165.5 \sim 166.8 \%$ for $40 \%$ level, and $178.5 \sim 189.8 \%$ for $60 \%$ level of prestressing, respectively. The reduction of ultimate load to failure is evaluated to be linear with corrosion ratio with high coefficient of determination (0.9658), so that prestressing level also has linear relationship with reduction of ultimate load in the same corrosive condition.

\section{Conflicts of Interest}

The authors declare that there are no conflicts of interest regarding the publication of this paper.

\section{Acknowledgments}

The authors appreciate the support from Basic Science Research Program through the National Research Foundation of Korea (NRF) funded by the Ministry of Science, ICT \& Future Planning (no. 2015R1A5A1037548) and grant from a Strategic Research Project (Development of Smart Prestressing System for Prestressed Concrete Bridges) funded 


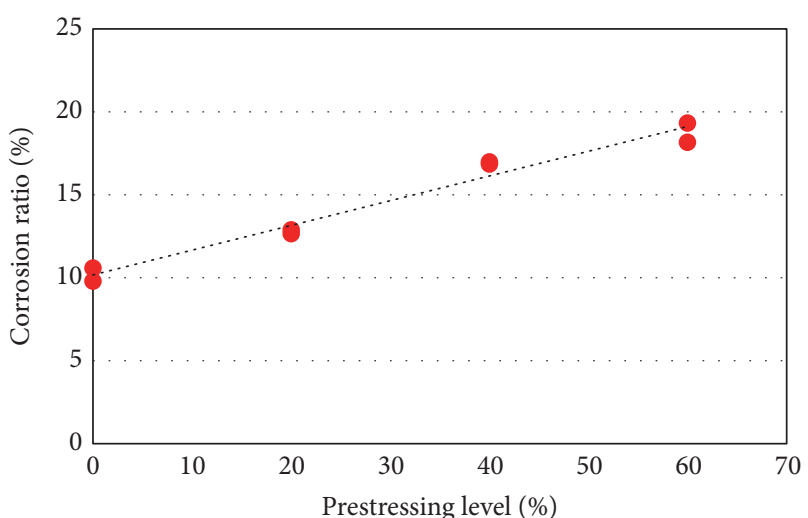

(a) Prestressing level and measured corrosion ratio in the tendon

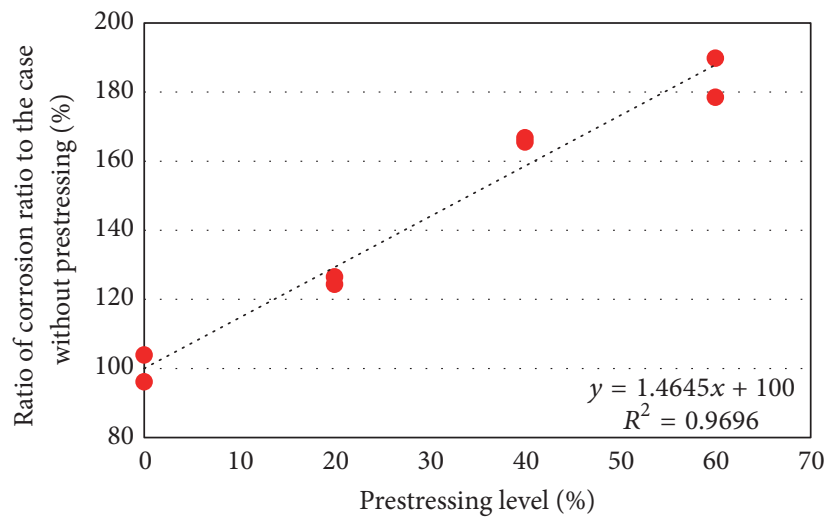

(b) Prestressing level and increasing ratio of accelerated corrosion ratio

FIGURE 10: Relationship between prestressing levels and corrosion behaviors.

by the Korea Institute of Civil Engineering and Building Technology (KICT).

\section{References}

[1] A. M. Neville, Concrete Technology, Prentice Hall, 2010.

[2] American Concrete Institute, "Building code requirements for structural concrete and commentary," ACI 318-11, ACI Committee 440, 2011.

[3] Z. Zhou, J. P. He, G. D. Chen, and J. P. Ou, "A smart steel strand for the evaluation of prestress loss distribution in posttensioned concrete structures," Journal of Intelligent Material Systems and Structures, vol. 20, no. 16, pp. 1901-1912, 2009.

[4] F.-Z. Xuan, H. Tang, and S.-T. Tu, "In situ monitoring on prestress losses in the reinforced structure with fiber-optic sensors," Measurement, vol. 42, no. 1, pp. 107-111, 2009.

[5] F. Li, Y. Yuan, and C.-Q. Li, "Corrosion propagation of prestressing steel strands in concrete subject to chloride attack," Construction and Building Materials, vol. 25, no. 10, pp. 38783885, 2011.

[6] F. Li and Y. Yuan, "Effects of corrosion on bond behavior between steel strand and concrete," Construction and Building Materials, vol. 38, pp. 413-422, 2013.

[7] A. P. Halsall, W. E. Welch, and S. M. Treparier, "Acoustic monitoring technology for concrete structures," in Proceeding of the FIP Symposium 1996 on Post-Tensioned Concrete Structures, pp. 483-491, The Concrete Society, 1996.

[8] R. J. Woodward and F. W. Williams, "Collapse of YNS-Y-GWAS bridge, GLAMORGAN," Proceedings of the Institute of Civil Engineers, vol. 84, part 1, pp. 635-669, 1988.

[9] Z. Zhao-Hui Lu, F. Li, and Y. G. Zhao, in Proceeding of the 4th International Conference of the Durability of Concrete Structures, pp. 57-65, Purdue University, USA, 2016.

[10] European-Standard, “Design of concrete structure," EN 1992-1$1,2004$.

[11] Japan Society of Civil Engineering, Standard specification for concrete structures-Design, JSCE- Guidelines for Concrete, 15 edition, 2012.

[12] S. H. Kim, J. G. Choi, S. M. Ham, and W. H. Heo, "Reliability evaluation of a PSC highway bridge based on resistance capacity degradation due to a corrosive environment," Applied Sciences, vol. 6, no. 12, p. 423, 2016.
[13] L. Dai, L. Wang, J. Zhang, and X. Zhang, "A global model for corrosion-induced cracking in prestressed concrete structures," Engineering Failure Analysis, 2015.

[14] W. Podolny Jr., "Corrosion of prestressing steels and its mitigation," Special Report, PCI Journal, pp. 34-55, 1992.

[15] H. Shuxian, W. Herbert, H. Rosemarie, D. Biqin, D. Peng, and $\mathrm{X}$. Feng, "Long-term monitoring of reinforcement corrosion in concrete using ground penetrating radar," Corrosion Science, vol. 114, no. 1, pp. 123-132, 2017.

[16] S. G. Youn, S. K. Cho, and E. K. Kim, "Acoustic emission technique for detection of corrosion-induced wire fracture," Key Engineering Materials, vol. 297-300, pp. 2040-2045, 2005.

[17] G. G. Clemena and W. T. McKeel, "Detection of delamination in bridge decks with infrared thermography," Transportation Research Record, no. 664, pp. 25-85, 1978.

[18] S. Baek, W. Xue, M. Q. Feng, and S. Kwon, "Nondestructive corrosion detection in RC through integrated heat induction and IR thermography," Journal of Nondestructive Evaluation, vol. 31, no. 2, pp. 181-190, 2012.

[19] J. P. Broomfield, Corrosion of Steel in Concrete: Understanding, Investigation and Repair, E\&FN, London, UK, 1997.

[20] MMFX Technologies Corp, "Comparative correlative corrosion testing and analysis of MMFX 2 rebars for reinforced concrete applications," WJE Final Report 2003.0707.0, 2008.

[21] S. J. Kwon and S. S. Park, "Non destructive technique for steel corrosion detection using heat induction and ir thermography," Journal of the Korea Institute for Structural Maintenance and Inspection, vol. 16, no. 2, pp. 40-48 (Chinese), 2012 (Korean).

[22] S. Sakurada, H. Irie, and Y. Yoshida, "Development of reinforced concrete corrosion amount presumption method by ultrasonic method," in Proceedings of the 17th World Conference on Nondestructive Testing, pp. 1-6, Shanghai, China, 2008. 

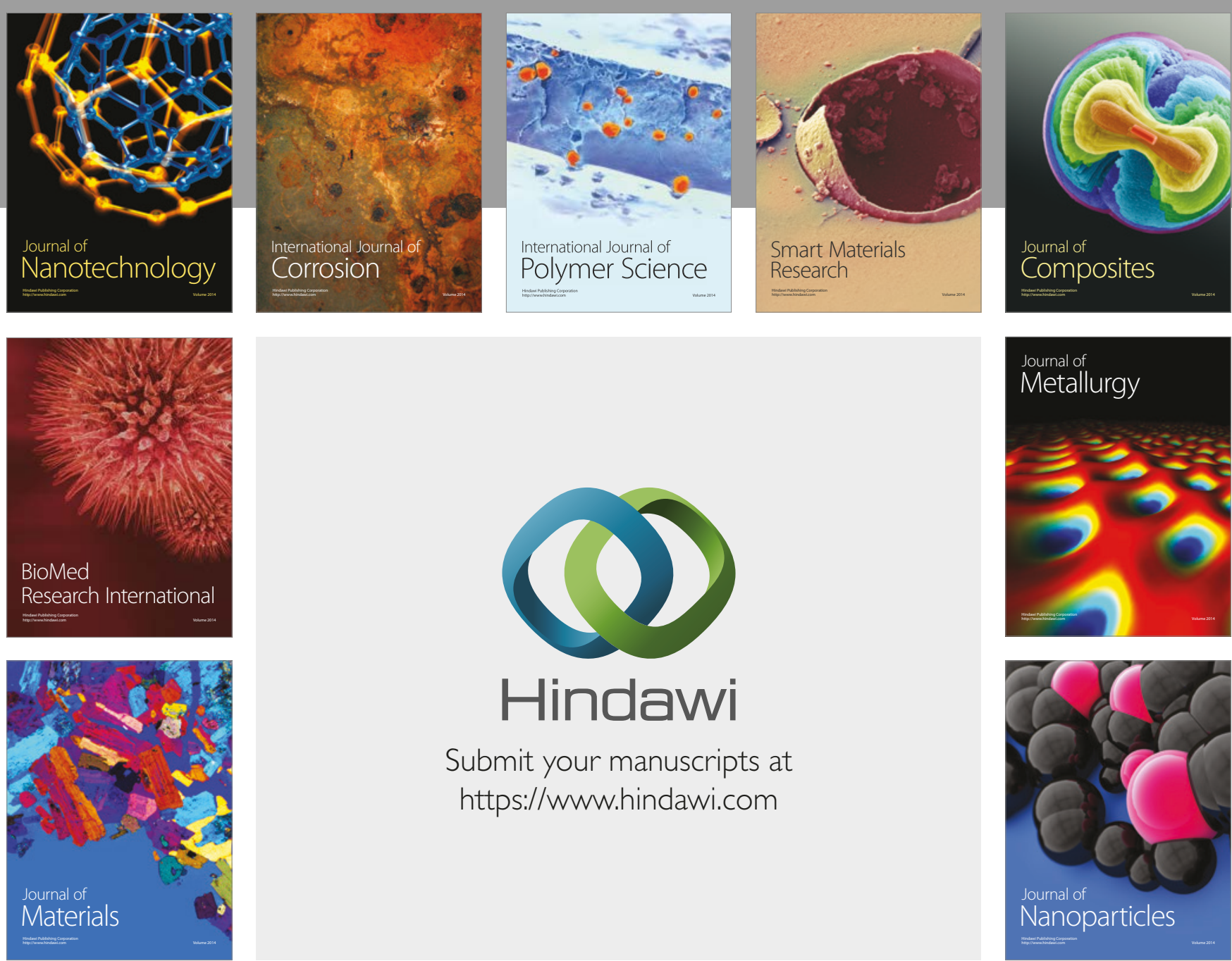

\section{Hindawi}

Submit your manuscripts at

https://www.hindawi.com
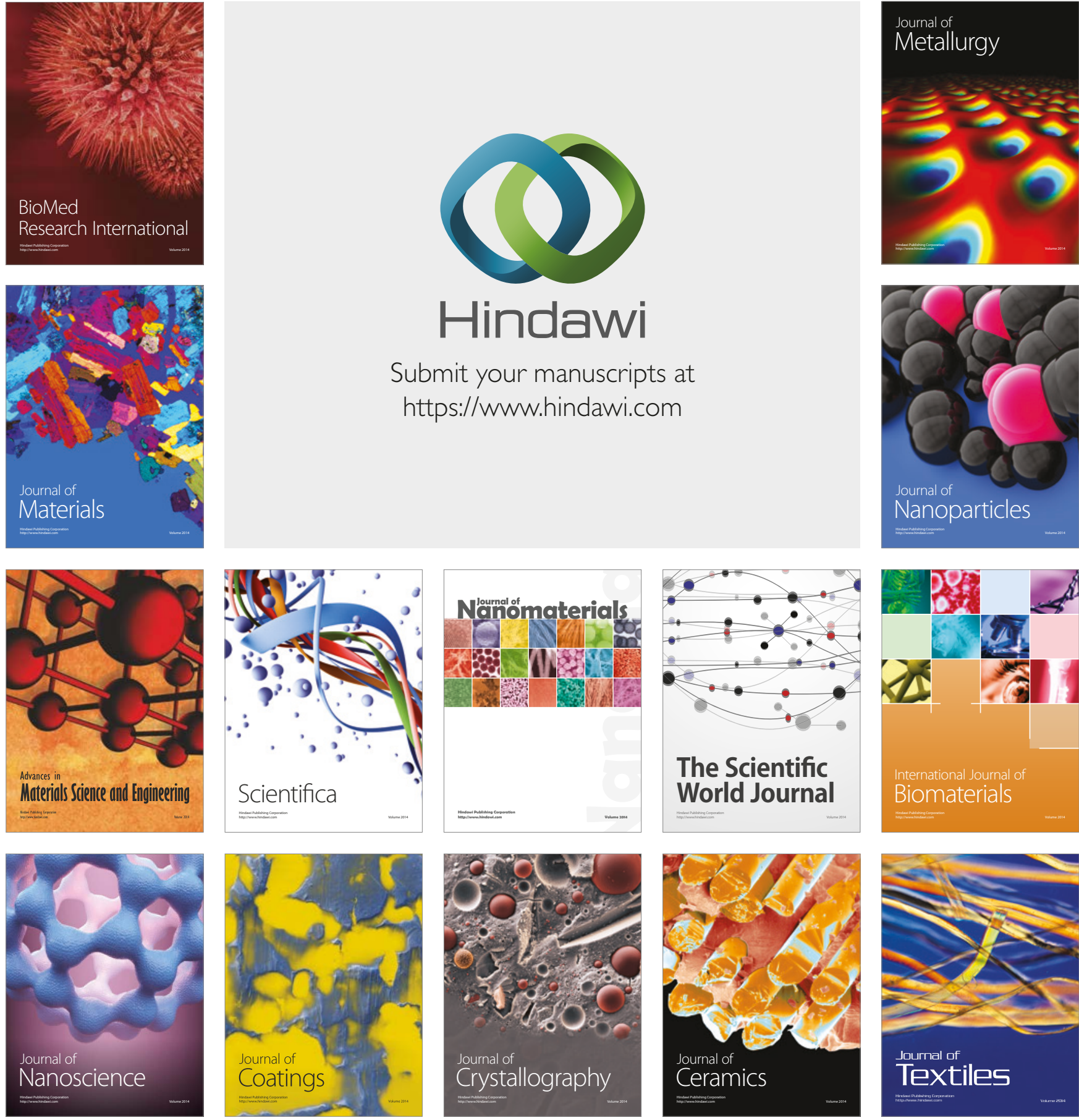

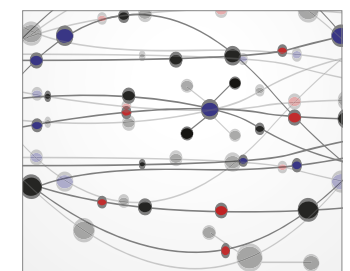

The Scientific World Journal
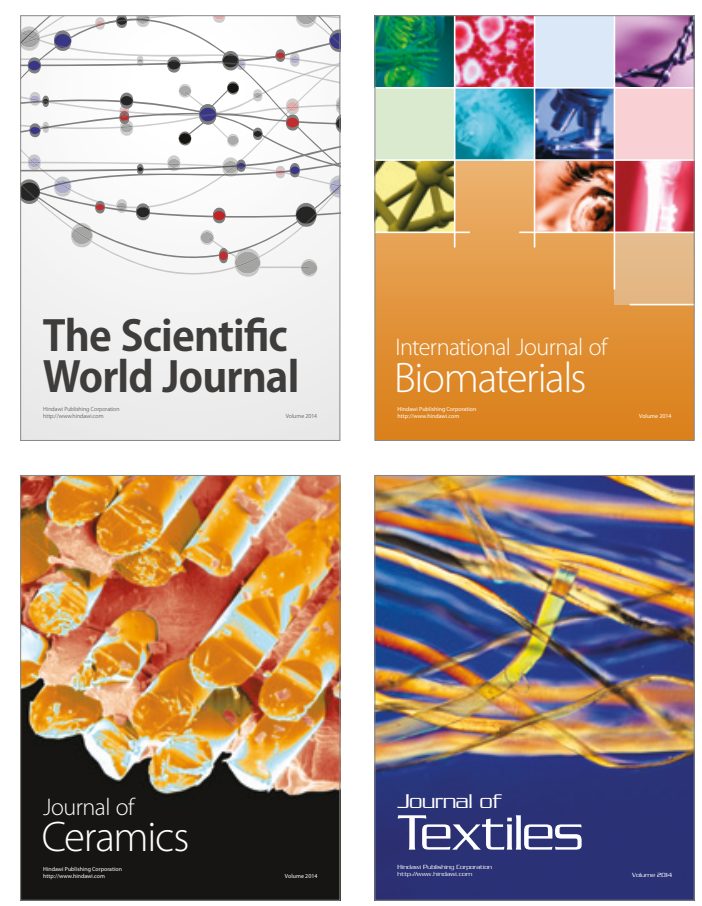